\title{
$B J R$ \\ Retrieval analysis of metal and ceramic femoral heads on a single CoCr stem design
}

\section{A. Di Laura, H. Hothi, J. Henckel, I. Swiatkowska, M. H. L. Liow, Y-M. Kwon,} J. A. Skinner, A. J. Hart

Institute of Orthopaedics and Musculoskeletal Science (University College London), Stanmore, United Kingdom

A. Di Laura, BEng, MSc, MPhil, PhD Candidate,

- H. Hothi, BSc, MSc, PhD, Orthopaedic Engineer,

J. Henckel, MBBS, MRCS, PhD, Orthopaedic Surgeon,

- I. Swiatkowska, MSc, PhD

Candidate,

J. A. Skinner, MBBS, FRCS (Eng), Orthopaedic Surgeon,

a. J. Hart, MA, MD, FRCSG (Orth), Orthopaedic Surgeon, Institute of Orthopaedics and Musculoskeletal Science, University College London and the Royal National Orthopaedic Hospital, Brockley Hill, Stanmore, Middlesex, HA7 4LP, UK.

M. H. L. Liow, MD, Orthopaedic Surgeon,

- Y-M. Kwon, MD, PhD, FRCS,

FRACS. Assistant Professor of

Orthopaedic Surgery, Department of Orthopaedic Surgery, Massachusetts General Hospital, Harvard Medical School, Boston, USA.

Correspondence should be sent to A. Di Laura;

email: anna.laura.14@ucl.ac.uk

doi: $10.1302 / 2046-3758.65 . B \mid R-$ 2016-0325.R1

Bone Joint Res 2017;6:345-350. Received: 7 December 2016; Accepted: 1 March 2017

\section{Objectives}

The use of ceramic femoral heads in total hip arthroplasty (THA) has increased due to their proven low bearing wear characteristics. Ceramic femoral heads are also thought to reduce wear and corrosion at the head-stem junction with titanium (Ti) stems when compared with metal heads. We sought to evaluate taper damage of ceramic compared with metal heads when paired with cobalt chromium ( $\mathrm{CoCr}$ ) alloy stems in a single stem design.

\section{Methods}

This retrieval study involved 48 total hip arthroplasties (THAs) with CoCr V40 trunnions paired with either $\mathrm{CoCr}(n=21)$ or ceramic $(n=27)$ heads. The taper junction of all hips was evaluated for fretting/corrosion damage and volumetric material loss using a roundnessmeasuring machine. We used linear regression analysis to investigate taper damage differences after adjusting for potential confounding variables.

\section{Results}

We measured median taper material loss rates of $0.210 \mathrm{~mm}^{3} /$ year $(0.030$ to 0.448$)$ for the metal head group and $0.084 \mathrm{~mm}^{3} /$ year $(0.059$ to 0.108$)$ for the ceramic group. The difference was not significant $(p=0.58)$. Moreover, no significant correlation between material loss and implant or patient factors $(p>0.05)$ was found.

\section{Conclusions}

Metal heads did not increase taper damage on CoCr trunnions compared with ceramic heads from the same hip design. The amount of material released at the taper junctions was very low when compared with available data regarding $\mathrm{CoCr} / \mathrm{Ti}$ coupling in metal-on-metal bearings.

\section{Cite this article: Bone Joint Res 2017;6:345-350.}

Keywords: Hip prostheses, Ceramic femoral heads, Metal femoral heads

\section{Article focus}

- It is currently unclear what effect the material selection of the femoral head has on the volume of material loss at the taper junction when CoCr femoral stems are used.

- We examined tapers of retrieved ceramicon-polyethylene and metal-on-polyethylene bearings paired with $\mathrm{CoCr}$ trunnions.

- We aimed to quantify the volume of material loss to understand if a difference exists between the materials examined.

\section{Key messages}

- We measured median taper material loss rates of $0.210 \mathrm{~mm}^{3} /$ year ( 0.030 to 0.448 ) for the metal head group and 0.084 $\mathrm{mm}^{3} /$ year (0.059 to 0.108) for the ceramic group. After adjusting for confounding factors, the groups were not found to differ significantly $(p=0.58)$.

- The use of metal heads with $\mathrm{CoCr}$ stems does not appear to result in the same volumes of material loss as seen when titanium stems are used.

\section{Strengths and limitations}

- The strength of this study is that only one implant design was investigated, thus reducing possible confounding variables.

- The implants examined are dual-taper in design and have likely failed due to damage at the neck-stem junction. However, this allowed us to view the state of the head-neck junction three years after implantation. 


\section{Introduction}

A growing number of surgeons are selecting ceramic femoral heads due to their established track record of minimising bearing surface wear but also more recently in an attempt at reducing metal release from the taper junction. This is reflected by registry data which show that the use of ceramic-on-polyethylene bearing combinations has doubled over the last five years in the United Kingdom and Australia, 1,2 and in the United States almost $50 \%$ of heads implanted are now made of ceramic. ${ }^{3}$

Mechanical wear and corrosion at the head-stem junction of total hip arthroplasties (THAs), commonly referred to as trunnionosis, has been reported since the late $1980 s^{4-9}$ and is generally associated with large-diameter metal-on-metal (LDMoM) bearings with titanium stems, ${ }^{10,11}$ which have been implicated in adverse tissue reactions ${ }^{12,13}$ and loss of implant integrity. ${ }^{14,15}$

To date, little is known about the metal released at the taper junctions in metal-on-polyethylene (MoP) or in ceramic-on-polyethylene (CoP) combinations. Moreover, the use of $\mathrm{CoCr}$ stems mating $\mathrm{CoCr}$ heads is thought to eliminate the galvanic effect due to the metal mismatch leading to less corrosive damage. ${ }^{16}$ Favourable outcomes have been shown when ceramic femoral heads are used, with low corrosion scores based on visual assessment ${ }^{17,18}$ and low volume of material loss at the head-stem junction. ${ }^{19}$

In this retrieval study, we examined a series of failed hips of a single design that differed only in the selection of the material of the femoral head: ceramic versus cobaltchromium alloy. We questioned whether the use of a ceramic head provides any additional benefit for reducing trunnionosis with $\mathrm{CoCr}$ stems versus using $\mathrm{CoCr}$ heads. Our objectives were: to compare the extent and severity of stem trunnion/head bore taper corrosion between ceramic and metal heads, and; to compare the volumes of material lost from the taper surfaces of the head-stem junctions of the two bearing types.

\section{Patients and Methods}

Implant and patient selection. This study involved a series of 48 retrieved THAs that were revised at a single institution and subsequently sent to our centre for analysis. All hips were of a dual-taper design, with two junctions: at the neck-stem and neck-head. This study focused on the retrieval findings at the neck-head surfaces.

The hips were all of a single Rejuvenate (Stryker Orthopaedics, Mahwah, New Jersey) design and consisted of $\mathrm{CoCr}$ alloy V40 trunnions that were paired with either $21 \mathrm{CoCr}$ alloy heads (Stryker) or 27 zirconia-toughened alumina (BIOLOX delta) ceramic heads (CeramTec GmbH, Plochingen, Germany). All heads were articulated against an ultra-high-molecular-weight polyethylene (UHMWPE) bearing. The CoCr heads had a median diameter of $40 \mathrm{~mm}$ (32 to 40) and the ceramic heads were all $36 \mathrm{~mm}$ in diameter except for one $32 \mathrm{~mm}$ head. Reasons for revision were pain, elevated blood metal ion levels and bony erosion due to severe corrosion at the neck-stem interface.

Patients with metal heads (11 female and ten male) had a median age of 66 years (42 to 81), a median implantation time of 23 months (19 to 59) and a median BMI of $28.7 \mathrm{~kg} / \mathrm{m}^{2}$ (25 to 42 ).

Patients with ceramic heads (11 female and 16 male) had a median age of 61 years (36 to 78), a median implantation time of 37.5 months (5 to 71) and a median BMI of $29 \mathrm{~kg} / \mathrm{m}^{2}$ (24 to 46.4).

The two groups were not found to vary in terms of their gender or body mass index (BMI) but there was some evidence that the age of revision varied between them, with the ceramic group younger, on average, by around seven years. However, this difference was only of borderline statistical significance. There was no difference in the length of implantation.

The two groups did not vary in terms of their head offset or lateral offset. The diameter of the metal heads was greater than that of the ceramic heads (Table I).

Sample preparation. All retrieved implants were decontaminated upon receipt by following an established protocol developed at our centre. The components were then cleaned in an ultrasonic cleaning bath (Pulsatron MKC6, Kerry, Guyson, UK) with a 10\% mild detergent solution for 30 minutes, followed by rinsing under water and then being allowed to dry in air; this was performed in order to eliminate obscuring factors such as proteinaceous films on the surfaces.

Taper corrosion assessment. The $\mathrm{CoCr}$ male trunnions were inspected visually and with the aid of a Leica M50 light microscope (Leica Microsystems, Mannheim, Germany), by two examiners (AD and $\mathrm{HH}$ ), experienced in retrieval analysis, to score for evidence of corrosion damage using a previously published method. ${ }^{20}$ A score of 1 indicated minimal fretting or corrosion (no corrosion damage); 2 indicated mild damage (corrosion attack confined to one or more small areas); 3 indicated moderate damage (aggressive local corrosion attack with corrosion debris); and 4 indicated severe damage (severe corrosion attack and abundant corrosion debris). The two examiners were blinded for head material and in the case of disagreement between them, a consensus score was achieved after consultation. The bore tapers of the metal heads were also assessed for severity of corrosion. We did not compare the scores for the head tapers between the two groups, given that the corrosion score is applicable to metal heads only and comparison between corrosion and metal transfer on ceramic would not have been of significance.

Each neck-stem interface was also assessed for corrosion using the method described above. ${ }^{20}$

Material loss measurement. The volume of material loss from the head bore taper surfaces was measured 
Table I. Patient and implant data showing median (range) values

\begin{tabular}{lll}
\hline & Metal heads $(\mathbf{n}=\mathbf{2 1})$ & Ceramic heads $(\mathbf{n}=\mathbf{2 7})$ \\
\hline Gender (male : female) & $10: 11$ & $16: 11$ \\
Age at surgery $(\mathrm{yrs})$ & $66(42$ to 81$)$ & $61(36$ to 78$)$ \\
Body mass index $\left(\mathrm{kg} / \mathrm{m}^{2}\right)$ & $28.7(25$ to 42$)$ & $29(24$ to 46.4$)$ \\
Implantation time $(\mathrm{mths})$ & $23(19$ to 59$)$ & $37.5(5$ to 71$)$ \\
Head diameter $(\mathrm{mm})$ & $40(32$ to 40$)$ & $36(32$ to 36$)$ \\
Head offset $(\mathrm{mm})$ & $0(-5$ to 4$)$ & 0.39 \\
Lateral offset $(\mathrm{mm})$ & $44.8(34.9$ to 46.7$)$ & $4.5)$ \\
\hline
\end{tabular}

*significant if $<0.05$.

Table II. Summary of the material loss analysis outcomes for each group, data presented as median (interquartile range IQR) rate $\mathrm{mm}^{3} /$ year

\begin{tabular}{lll}
\hline Outcome $\left(\mathbf{m m}^{\mathbf{3}} / \mathbf{y r}\right)$ & Metal Median (IQR) & Ceramic Median (IQR) \\
\hline Trunnion rate & $0.045(0.005$ to 0.077$)$ & $0.053(0.017$ to 0.079$)$ \\
Head rate & $0.112(0.032$ to 0.326$)$ & $0.013(0.001$ to 0.034$)$ \\
Total rate & $0.210(0.030$ to 0.448$)$ & $0.084(0.059$ to 0.108$)$ \\
\hline
\end{tabular}

$\mathrm{IQR}$, interquartile range.

using a Talyrond 365 (Taylor Hobson, Leicester, United Kingdom) roundness-measuring machine. A total of 180 vertical measurement traces were taken along the taper axis using a 5-micron diamond stylus, with the femoral head positioned on a rotating air spindle, levelled and centred with respect to the spindle axis. The vertical traces from each head taper were combined into a rectangular surface map and the unworn surface on the taper was manually selected in order to level the data obtained. ${ }^{11,21}$ The same method was used to analyse the male trunnion surfaces, and the annual rate of material loss was calculated by dividing the total volume by implantation time.

Scanning Electron Microscopy (SEM) and Energy Dispersive Spectroscopy (EDS). A scanning electron microscope (SEM) (Jeol JSM5500; Jeol Ltd, Tokyo, Japan) was used to characterise the fretting/corrosion damage occurring at the male trunnion surfaces mating either ceramic or metal heads in both secondary and backscattered modalities and, when appropriate, EDS for elemental analysis was performed.

Statistical analysis. Statistical analyses were performed using SPSS Statistics Version 23 (IBM, Armonk, New York). All continuous variables were found to be approximately normally distributed, and were compared between groups using the unpaired $t$-test. Categorical variables were analysed using the Fisher's exact test.

There were three outcome variables relating to the amount of material loss: trunnion rate; head rate, and; total (trunnion and head) rate.

All three variables were measured on a continuous scale, and all were found to have positively skewed distributions. As a result of the distributions, all outcomes were given a log transformation before analysis. Both trunnion rate and head rate had some zero values, and thus to enable a log transformation to be applied, a small constant was added to all rates before transformation. Regression analyses were performed to compare the wear rate between the two groups. The first analysis examined the difference between groups without considering any further variables. The second analysis re-examined the group difference, adjusting for potential confounding factors found to show a difference $(p<0.2)$ between the groups in preliminary analysis. The analysis of the outcomes was performed using linear regression on the log-transformed values.

Spearman's rank order correlation was used to identify correlations between corrosion scores, material loss rates and the clinical and implant variables considered in this study. The level of significance chosen for all statistical analyses was $p<0.05$.

\section{Results}

Taper corrosion assessment. The mean corrosion scores of the trunnions paired with metal and ceramic heads were 2.3 ( 1 to 4 ) and 2.5 ( 1 to 4 ), respectively; this difference was not significant (t-test, $p=0.48$ ). The mean corrosion score for the metal head tapers was 2.7 (1 to 4).

Severe corrosion damage was seen for all implants at the neck-stem interface with a mean Goldberg corrosion score of 3.95 ( 3 to 4 ) for the neck male parts and 3.88 (3 to 4 ) for the stem bore tapers.

Material loss measurement. Table II presents the median (IQR) material loss rates at the trunnion head taper and the total volumetric losses ( $\mathrm{mm}^{3} /$ year) for the two groups. The total head-stem rate with metal and ceramic heads had a median of $0.210 \mathrm{~mm}^{3} /$ year (0.030 to 0.448 ) and $0.084 \mathrm{~mm}^{3} /$ year $(0.059$ to 0.108$)$ respectively.

Scanning Electron Microscopy and Energy Dispersive Spectroscopy. We found evidence of mechanically assisted crevice corrosion at trunnions that had been paired with both head types. Dark deposits were found to be chromium-rich, indicative of corrosion processes.

Regression analysis. The results of our statistical analysis are summarised in Table III. The group differences are reported in the form of ratios, along with corresponding confidence intervals. These give the ratio of material loss in the ceramic group relative to metal group. P-values from our linear regression analysis are also reported. 
Table III. Summary of the regression analysis results. Due to the log transformation of the outcomes, the group differences are reported in the form of ratios, along with corresponding confidence intervals. These give the ratio of material loss in the ceramic group relative to metal group

\begin{tabular}{llll}
\hline Outcome & Analysis & Ratio $(\mathbf{9 5 \%} \mathbf{C I})^{*}$ & p-value \\
\hline Trunnion rate & Unadjusted & $1.16(0.58$ to 2.33$)$ & 0.66 \\
& Adjusted $^{\dagger}$ & $1.56(0.52$ to 4.46$)$ & 0.41 \\
\multirow{2}{*}{ Head rate } & Unadjusted $^{*}$ & $0.26(0.10$ to 0.68$)$ & 0.007 \\
\multirow{2}{*}{ Total rate } & Adjusted $^{\dagger}$ & $0.42(0.10$ to 1.71$)$ & 0.22 \\
& Unadjusted $^{*}$ & $0.60(0.20$ to 1.81$)$ & 0.35 \\
& Adjusted $^{\dagger}$ & $1.56(0.30$ to 8.00$)$ & 0.58 \\
\hline
\end{tabular}

* Ratio calculated as rate in ceramic group relative to rate in metal group.

${ }^{\dagger}$ Adjusted for age at revision, length of implantation and head diameter.

Our results suggested no significant difference between metal and ceramic groups in either trunnion rate or cumulative material loss rate. The lack of significance for these outcomes was observed both in a simple comparison (unadjusted analysis), and after adjusting for potentially confounding factors.

There was a significant difference in head taper material loss rate between the groups in the unadjusted analysis (unpaired t-test, $p=0.007$ ). After adjusting for potentially confounding factors, the head rate in the ceramic group was still lower (in terms of the estimated difference), but this difference was not statistically significant $(p=0.22)$.

Correlation analysis. We did not find a significant correlation between material loss or patient variables of gender (Spearman's rho $=0.35, p=0.33$ ), age at surgery (Spearman's rho $=-0.42, p=0.19$ ), BMI (Spearman's rho $=0.37, p=0.50$ ), implantation time (Spearman's rho $=-0.16, p=0.63)$ or implant variables of head diameter (Spearman's rho $=0.31, p=0.36$ ), head offset (Spearman's rho $=0.42, p=0.21$ ) and lateral offset (Spearman's rho $=-0.11, p=0.83$ ) in the metal group. Similarly, taper material loss in the ceramic group was not affected by patient or implant factors $(p>0.05)$ (Table IV).

Stem trunnion corrosion for the metal group was not significantly correlated with gender (Spearman's rho $=0.21$, $p=0.41$ ), age at surgery (Spearman's rho $=-0.17, p=0.49$ ), BMI (Spearman's rho $=0.27, \mathrm{p}=0.67$ ), implantation time (Spearman's rho $=-0.44, p=0.06$ ) or implant variables of head diameter (Spearman's rho $=-0.09, p=0.70$ ), head offset (Spearman's rho $=0.33, p=0.17$ ) and lateral offset (Spearman's rho $=-0.29, p=0.40$ ). The head taper corrosion score was not correlated with any patient or implant variables, $\mathrm{p}>0.05$.

Stem trunnion score for the ceramic group was not correlated with gender (Spearman's rho $=0.37, p=0.06$ ), BMI (Spearman's rho $=-0.48, p=0.15$ ), implantation time (Spearman's rho $=0.11, p=0.60$ ) or implant variables of head diameter (Spearman's rho $=-0.09, p=0.62$ ), head offset (Spearman's rho $=0.12, p=0.54$ ) and lateral offset (Spearman's rho $=-0.32, p=0.34$ ); however there was $a$ negative correlation between trunnion corrosion and age at surgery (Spearman's rho $=-0.42, p=0.03$ ).

There was a positive correlation between visual scoring and volumetric material loss $\left(\mathrm{mm}^{3}\right)$ in the ceramic group (Spearman's rho $=0.69, p=0.0002$ ) for the stem trunnions. No other significant correlations were found.

\section{Discussion}

This is one of the first studies to quantify differences in taper junction material loss as a means of evaluating the in vivo performance of ceramic heads compared with metal heads. This study involved approximately 50 hips, all of one design that differed only in the material of the femoral head. Our adjusted regression analysis revealed that there was no difference in the rate of material loss at the head-stem surfaces between the two head materials. The rates of total material loss were as much as ten times lower than previously reported data investigating LDMoM hips. ${ }^{10,11}$

The use of ceramic femoral heads has primarily been advocated on the basis of their advanced bearing wear resistance. Few studies have reported on taper corrosion involving ceramics heads on metal stems ${ }^{17-18,22-23}$ and, to our knowledge, there is only one other study quantifying volumetric material loss. ${ }^{19}$ Moreover, there is very little data on material loss for the Morse taper in MoP hips. ${ }^{16,19}$ The magnitude of material lost estimated in this study was very low in comparison with available data on MoM implants, in both groups. ${ }^{10,11}$ This is in agreement with what Kocagoz et al $^{19}$ have found, however, contrary to the findings of this previous study, we did not see a significant difference between metal and ceramic heads. The difference between this investigation and the one conducted by Kocagoz et al $^{19}$ is probably attributable to the material combination; we analysed implants with stems made of $\mathrm{CoCr}$ alloy, whereas the majority of stems in the previous study were made of titanium alloy, which is known to increase the effects of galvanic corrosion. ${ }^{7}$ Our data is, however, in agreement with previous data reporting on the same material combination considered here. ${ }^{16}$ The study examined tapers of retrieved metal-onpolyethylene hips that had been revised for reasons other than adverse tissue reactions and reported a median rate of material loss of $00.084 \mathrm{~mm}^{3} /$ year; the rate was considered to be clinically insignificant.

We acknowledge several limitations of the current study. The stems used for the investigation were of a recalled dual-taper design which we speculate failed due to adverse reaction to metal debris generated at the neckstem interface as severe corrosion was observed at time of revision and retrieval examination. These components, together with the ABG II design (Stryker), have been implanted in 30000 patients worldwide. Their analysis has allowed us to compare ceramic and metal heads of a single design; this is normally difficult in retrieval analysis 
Table IV. Correlation between patient and implant variables with total losses ( $\mathrm{mm}^{3} / \mathrm{year}$ ) in both material combination groups

\begin{tabular}{|c|c|c|c|c|}
\hline \multirow[t]{2}{*}{ Variable } & \multicolumn{2}{|l|}{ Metal } & \multicolumn{2}{|l|}{ Ceramic } \\
\hline & Spearman's rho & p-value & Spearman's rho & p-value \\
\hline Gender & 0.35 & 0.33 & 0.13 & 0.69 \\
\hline Age at surgery & -0.42 & 0.19 & -0.08 & 0.77 \\
\hline Body mass index & 0.37 & 0.50 & -0.23 & 0.58 \\
\hline Implantation time & -0.16 & 0.63 & -0.21 & 0.45 \\
\hline Head diameter & 0.31 & 0.36 & - & - \\
\hline Head offset & 0.42 & 0.21 & -0.25 & 0.29 \\
\hline Lateral offset & -0.11 & 0.83 & -0.14 & 0.73 \\
\hline
\end{tabular}

studies as ceramic heads are less readily available than metal heads due to their good clinical performance. Another limitation is the greater head size in the metal group. Head diameter is a significant variable between the two groups. A larger head size is known to increase frictional torque at the junction and therefore also increase the volume of material loss, and this may partially explain the greater material loss seen in the metal heads. However, when we controlled for this variable statistically, the difference between the two groups proved not to be statistically significant. We also acknowledge the small sample size as a limitation. Although the statistical analysis suggests that the difference between the two groups is not significant, the volume loss at the junction in the $\mathrm{CoCr}$ CoCr group is of an order of magnitude greater than that of the ceramic-CoCr group. This lack of statistical significance could be due to a low sample size; however, the main question is whether the difference is clinically meaningful. In this respect, it is currently unclear as to how much material loss and corrosion must occur at the taper junction to be of clinical significance. In the present study, the losses were very low $\left(<1 \mathrm{~mm}^{3} /\right.$ year $)$ and these volumes were found to be clinically insignificant in recent research on the same metal alloy couple. ${ }^{16}$

While we found no statistical difference between the two cohorts in relation to quantified material loss, it is important to consider differences in terms of metal release, which is known to be toxic in elevated doses and cause adverse body reactions; ${ }^{24-27}$ there is naturally a difference between the two material combinations. This is due to the fact that in the ceramic-CoCr couple, only the $\mathrm{CoCr}$ surfaces are involved in the corrosion processes due to the electrically insulating nature of ceramics.

From our work, the use of $\mathrm{CoCr}$ heads with $\mathrm{CoCr}$ stems seems to perform as well as metal-ceramic stemtaper combinations in articulation with UHMWPE. In support of this, the Australian Registry ${ }^{3}$ shows no statistical difference in the long-term performance of MoP and CoP bearing combinations. Any metal in the human body experiences a certain amount of degradation. Thus, there is likely to be a certain quantity of metal released from the implant, probably clinically insignificant, that the body can tolerate without severe reaction.
Recent attention has been brought to the phenomenon of trunnionosis in MoP hips ${ }^{9,8,28,29}$ and the fact that, when it occurs, the effects can be as severe as when a MoM bearing is involved. ${ }^{30}$ However, failures involving MoP hip arthroplasties constitute a rare event with only a few reported cases in the literature. Ceramic heads do not completely eliminate the damage at the head-stem junction as mechanically assisted crevice corrosion still occurs. Nonetheless, we noticed significantly less damage when compared with LDMoM hips.

The strength of this study is that only one implant design was investigated, with the head material being the only difference, thus reducing possible confounding variables. We acknowledge that the results of this study are directly applicable only to the specific design examined, however, the study provides comparable data for future research in this topic as well as new insights into the evaluation of the in vivo performance of hip implants.

In conclusion, the use of either $\mathrm{CoCr}$ or ceramic heads on $\mathrm{CoCr}$ stems resulted in low taper material loss rates in comparison with previous data where Ti stems have been used. Our study suggests that ceramic and $\mathrm{CoCr}$ heads perform equally with respect to corrosion and material loss, statistically speaking, in this particular design and material pairing. Although the use of $\mathrm{CoCr}$ stems is decreasing due to concerns regarding stem corrosion, ${ }^{31,32}$ as well as the recognised biocompatibility of titanium, our results are still reassuring for patients with the material combinations discussed in this study.

\section{References}

1. No authors listed. AJRR American Joint Replacement Registry. Annual Report 2014. http://www.ajrr.net/images/annual_reports/AJRR_2014_Annual_Report_ final_11-11-15.pdf (date last accessed 07 March 2017).

2. No authors listed. NJR National Joint Registry. 12th Annual Report 2015. National Joint Registry for England, Wales, and Northern Ireland. http://www.njrcentre.org. uk/njrcentre/Portals/0/Documents/England/Reports/12th\%20annual\%20report/ NJR\%200nline\%20Annual\%20Report\%202015.pdf (date last accessed 07 March 2017).

3. No authors listed. Australian Orthopaedic Association National Joint Replacement Registry. Annual Report 2014. https://aoanjrr.sahmri.com/documents/10180/172286/ Annual\%20Report\%202014. (date last accessed 07 March 2017).

4. Collier JP, Surprenant VA, Jensen RE, Mayor MB, Surprenant HP. Corrosion between the components of modular femoral hip prostheses. J Bone Joint Surg [Br] 1992;74-A:511-517. 
5. Gilbert JL, Buckley CA, Jacobs JJ. In vivo corrosion of modular hip prosthesis components in mixed and similar metal combinations. The effect of crevice, stress, motion, and alloy coupling. J Biomed Mater Res 1993;27:1533-1544.

6. Cook SD, Barrack RL, Baffes GC, et al. Wear and corrosion of modular interfaces in total hip replacements. Clin Orthop Relat Res 1994;298:80-88.

7. Gilbert $\mathbf{J}$, Jacobs $\mathbf{J}$. The mechanical and electrochemical processes associated with taper fretting crevice corrosion: a review. In D.E. Marlow, J.E. Parr, M.B. Mayor Eds. Modularity of orthopedic implants. West Conshocken: ASTM International, 1997:45-59.

8. Lucas LC, Buchanan RA, Lemons JE. Investigations on the galvanic corrosion of multialloy total hip prostheses. J Biomed Mater Res 1981;15:731-747.

9. Lieberman JR, Rimnac CM, Garvin KL, Klein RW, Salvati EA. An analysis of the head-neck taper interface in retrieved hip prostheses. Clin Orthop Relat Res 1994;300:162-167.

10. Langton DJ, Sidaginamale R, Lord JK, Nargol AV, Joyce TJ. Taper junction failure in large-diameter metal-on-metal bearings. Bone Joint Res 2012;1:56-63.

11. Matthies AK, Racasan $\mathbf{R}$, Bills $\mathbf{P}$, et al. Material loss at the taper junction of retrieved large head metal-on-metal total hip replacements. J Orthop Res 2013;31:1677-1685.

12. Doorn PF, Mirra JM, Campbell PA, Amstutz HC. Tissue reaction to metal on metal total hip prostheses. Clin Orthop Relat Res 1996;329:S187-S205.

13. Gill IP, Webb J, Sloan K, Beaver RJ. Corrosion at the neck-stem junction as a cause of metal ion release and pseudotumour formation. J Bone Joint Surg [Br] 2012;94-B:895-900

14. Jacobs JJ, Gilbert JL, Urban RM. Corrosion of metal orthopaedic implants. J Bone Joint Surg [Am] 1998;80-A:268-282.

15. Gilbert JL, Buckley CA, Jacobs JJ, Bertin KC, Zernich MR. Intergranula corrosion-fatigue failure of cobalt-alloy femoral stems. A failure analysis of two implants. J Bone Joint Surg [Am]1994;76-A:110-115.

16. Hothi HS, Kendoff D, Lausmann C, et al. Clinically insignificant trunnionosis in largediameter metal-on-polyethylene total hip arthroplasty. Bone Joint Res 2017;6:52-56.

17. Hallab NJ, Messina C, Skipor A, Jacobs JJ. Differences in the fretting corrosion of metal-metal and ceramic-metal modular junctions of total hip replacements. J Orthop Res 2004;22:250-259.

18. Huot Carlson JCH, Van Citters DW, Currier JH, et al. Femoral stem fracture and in vivo corrosion of retrieved modular femoral hips. J Arthroplasty 2012;27:1389-1396

19. Kocagoz SB, Underwood RJ, MacDonald DW, Gilbert JL, Kurtz SM. Ceramic Heads Decrease Metal Release Caused by Head-taper Fretting and Corrosion. Clin Orthop Relat Res 2016;474:985-994.

20. Goldberg JR, Gilbert JL, Jacobs JJ, et al. A multicenter retrieval study of the taper interfaces of modular hip prostheses. Clin Orthop Relat Res 2002;401: 149-161.

21. Hothi HS, Matthies AK, Berber R, et al. The reliability of a scoring system for corrosion and fretting, and its relationship to material loss of tapered, modular junctions of retrieved hip implants. J Arthroplasty 2014;29:1313-1317.
22. Kurtz SM, Kocagöz SB, Hanzlik JA, et al. Do ceramic femoral heads reduce taper fretting corrosion in hip arthroplasty? A retrieval study. Clin Orthop Relat Res 2013:471:3270-3282

23. Urban RM, Jacobs JJ, Gilbert JL, et al. Characterization of solid products of corrosion generated by modular-head femoral stems of different designs and materials. In: In Marlowe DE, Parr JE, Mayor MB, eds. Modularity of Orthopedic Implants. STP 1301. ASTM International, 1997.

24. Fricka KB, Ho H, Peace WJ, Engh CA. Metal-on-metal local tissue reaction is associated with corrosion of the head taper junction. J Arthroplasty 2012;27:26-31.

25. Cooper HJ, Della Valle CJ, Berger RA, et al. Corrosion at the head-neck taper as a cause for adverse local tissue reactions after total hip arthroplasty. J Bone Joint Surg [Am]2012;94-A:1655-1661.

26. Srinivasan A, Jung E, Levine BR. Modularity of the femoral component in total hip arthroplasty. J Am Acad Orthop Surg 2012;20:214-222.

27. Scully WF, Teeny SM. Pseudotumor associated with metal-on-polyethylene total hip arthroplasty. Orthopedics. 2013 May 1;36(5):e666-670.

28. Cook RB, Bolland BJ, Wharton JA, et al. Pseudotumour formation due to tribocorrosion at the taper interface of large diameter metal on polymer modular total hip replacements. J Arthroplasty 2013;28:1430-1436.

29. Whitehouse MR, Endo M, Zachara S, et al. Adverse local tissue reactions in metal-on-polyethylene total hip arthroplasty due to trunnion corrosion: the risk of misdiagnosis. Bone Joint J 2015;97-B:1024-1030.

30. Svensson 0, Mathiesen EB, Reinholt FP, Blomgren G. Formation of a fulminant soft-tissue pseudotumor after uncemented hip arthroplasty. A case report. J Bone Joint Surg [Am] 1988;70-A:1238-1242.

31. Bryant $\mathbf{M}$, Ward $\mathbf{M}$, Farrar $\mathbf{R}$, et al. Characterisation of the surface topography, tomography and chemistry of fretting corrosion product found on retrieved polished femoral stems. J Mech Behav Med Biomet Mat 2014;32:321-334.

32. Hothi HS, Berber R, Panagiotopoulos AC, et al. Clinical significance of corrosion of cemented femoral stems in metal-on-metal hips: a retrieval study. Int Orthop 2016; $40: 2247-2254$

Funding Statement

None declared.

Author Contribution

A. Di Laura: Study design, Data acquisition, Data analysis, Writing of manuscript.

- H. Hothi: Study design, Data analysis, Writing of manuscript.

J. Henckel: Study design, Data analysis, Writing of manuscript.

- I. Swiatkowska: Data acquisition, Writing of manuscript.

- M. H. L. Liow: Data acquisition, Writing of manuscript.

Y-M. Kwon: Study design, Data acquisition, Data analysis, Writing of manuscript.

J. A. Skinner: Study design, Data acquisition, Data analysis, Writing of manuscript.

A. J. Hart: Study design, Data acquisition, Data analysis, Writing of manuscript.

ICMJE Cconflicts of Interest

None declared.

(c) 2017 Di Laura et al. This is an open-access article distributed under the term of the Creative Commons Attributions licence (CC-BY-NC), which permits unrestricted use, distribution, and reproduction in any medium, but not for commercial gain, provided the original author and source are credited. 